\title{
Measured Statistical Characteristics and Narrow-Band Teletype Message Errors on a Single-Sideband 600- Mile-Long Ultrahigh-Frequency Tropospheric Radio Link
}

\author{
E. F. Florman * and R. W. Plush*
}

(October 14, 1959)

\begin{abstract}
Measurements of a 417 megacycles per second unmodulated radio carrier over a 600 mile tropospheric path indicated that the variations of the received carrier envelope amplitude with time over 30-minute periods roughly approximated a Rayleigh distribution in the majority of the tests. Cumulative time distributions of the carrier fade durations were obtained over a range of carrier envelope power levels and were found to resemble corresponding distributions for narrow band thermal noise. The fade rate of the carrier envelope, at the median power level, was less than 0.2 cycle per second; this comparatively low fade rate is thought to be due mainly to the narrow $\left(1^{\circ}\right)$ antenna beam widths that were used and the consequent low order of multipath propagation of the radio waves. The half hour median power levels of the received carrier varied over a range of approximately \pm 8 decibels. The effective low-pass bandwidth of the carrier envelope spectrum was found to vary from 0.06 to 0.17 cycle per second. The measured median transmission loss was approximately 183 decibels which is within 3.5 decibels of the calculated value for the summer afternoon hours covered by the tests.

With antennas spaced (normal to the path) at each end by 150 wavelengths it was found that parallel-path, divergent-path, or convergent-path types of transmission gave crosscorrelation coefficients of the carrier envelopes which ranged from 0.08 to 0.20 . For the same antenna spacing but using crossed-path type of transmission, the cross-correlation coefficient was 0.57. Diversity measurements of single-path crossed polarization type of transmission indicated that the cross-correlation coefficient of the carrier envelopes was very close to unity.

Nondiversity narrow-band FSK error measurements indicated that an 18-decibel signal-to-noise power ratio over an effective bandwidth of 290 cycles per second (at the limiter-discriminator input) for a fading signal resulted in 0.8 percent binary errors and 4.0 percent teletype character errors. Extrapolation of these results indicates that a signal-tonoise ratio of 27 decibels is required to reduce the teletype character error rate to 0.1 percent in the same effective bandwidth.
\end{abstract}

\section{Introduction}

The performance of a tropospheric beyond-thehorizon radio communication system involves the study of the dependence of tropospheric radio wave propagation characteristics on frequency, path length, antenna beam widths, angular distance, meteorological conditions, antenna spacing, etc. Experimental data on a variety of tropospheric paths appear to indicate the feasibility of considering the radiofrequency carrier as being roughly equivalent to random noise passing through a narrow band filter. The limits of the simulating system are being determined by experimental measurements on tropospheric radio links under conditions covering a wide range of frequencies, path lengths, and other pertinent factors.

The work covered by this report was carried out in order to obtain experimental data on the statistical behavior of tropospheric uhf radio wave propagation over a 600-mile path. This system represents to date the longest operating tropospheric radio link and also employs very narrow antenna beam widths of approximately $1 \mathrm{deg}$; hence, it represents extremes as re-

*Central Radio Propagation Laboratory, National Bureau of Standards, Boulder, Colo. gards both length of path and antenna beam width.

The information obtained on the tropospheric radio signals is to be applied in studies involving various types of modulation for the purpose of establishing engineering standards of performance.

\section{Equipment and Technique}

The tropospheric radio link used to make the experimental measurements was the "Domestic Dew Drop" system designed by Lincoln Laboratory personnel and constructed by the General Electric Co., with assistance in the installation work from the Page Engineering Co. The military designation of this system is $\mathrm{AN} / \mathrm{FRC}-47$.

A total of twenty-seven 30-min tests were made during the period from July 10 to 16,1958 , covering times of day ranging from 0900 to 2400 e.s.t. In addition, one test was made on May 22, 1958; further tests could not be made at that time due to the fact that the system was undergoing a series of adjustments. Horizontally polarized waves were received on 23 of the tests and a combination of horizontally polarized and vertically polarized waves were received on the remaining 5 tests. Two radio receiver 
systems were used for tests Nos. 4 to 28 inclusive in order to obtain either space diversity data or to separate two signals which were being transmitted simultaneously over the same link at slightly different frequencies. Each radio receiving system was calibrated in terms of absolute input power levels before each test by means of a calibrated Micropot ${ }^{1}$ as indicated in figure 1. Cross coupling between the

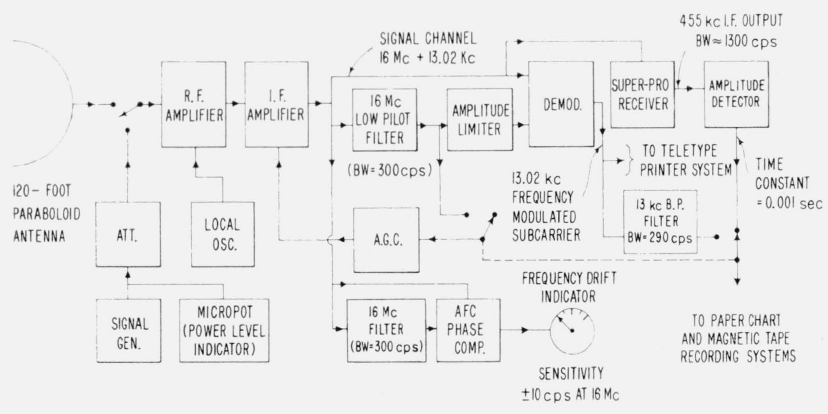

FIgure 1. Block diagram of receiving system.

horizontally and vertically polarized receiving antennas was down $40 \mathrm{db}$. Radio transmission, at a carrier frequency of $417.05 \mathrm{Mc}$ was from Millstone Hill, Mass., to Sauratown Mt., N.C.; the great circle path length being 638 miles.

Figure 1 is a block diagram of the radio receiving system used to carry out the tests. As indicated in the diagram, the system was arranged to be used either as a linear amplifier without $\mathrm{AGC}$ action or as a constant output-signal device with AGC action. When used as a linear system to obtain a measure of the propagation characteristics of the path, the received signal was taken from the $16-\mathrm{Mc}$ IF output of the uhf tropospheric link radio receiver and amplified through a $\mathrm{HF}$ communications type of radio receiver. The 455-kc IF output of the communication receiver was then passed through an amplitude detector having an output circuit time constant of $0.001 \mathrm{sec}$ and the resulting amplitude variations, which were representative of the amplitude variations of the carrier envelope, were recorded as frequency modulation of a subcarrier on magnetic tape. The output of the above amplitude detector was also recorded on paper in order to provide a visual check on the results. At the same time, amplitude distribution data on the carrier envelope were obtained by means of an array of counters each of which was adjusted to trigger at a different power level. A comparison of the amplitude distribution curves obtained directly at the receiving site with corresponding curves taken from the magnetic tape recording showed an overall discrepancy of less than $\pm 0.5 \mathrm{db}$.

During some of the tests involving teletype and binary message errors, power was transmitted simultaneously at frequencies of 417.05 and $417.06302 \mathrm{Mc}$ by utilizing a sideband $13.02 \mathrm{kc}$ above the carrier (low pilot) frequency. In this case, AGC was used

1 Furnished and calibrated by Section 1, Division 84, National Bureau of Standards, Boulder, Colo. This device was stated to have an absolute accuracy of \pm 3 percent. and a FSK teletype or a binary signal was taken from the demodulator output of the General Electric receiver, passed through a 13.02 -kc band pass filter (having an "effective" pass band of $290 \mathrm{cps}$ ), and then recorded directly on magnetic tape. This tape recording constituted a replica of the teletype (or binary) frequency modulation imposed on the 13.02-kc subcarrier at the radio transmitter; it includes propagation and radio receiver noise as well as carrier fading effects. The teletype signal consisted of the standard "quick brown fox" message which was also recorded by means of a teletype printer. The 10-cps binary signal (see fig. 10) was a voltage wave having a rise time of approximately $10 \mathrm{msec}$, and a flat-top duration of 30 milliseconds; this binary signal was generated by sending a continuous string of O's. A binary signal rate of $10 \mathrm{cps}$ was the maximum. frequency practically attainable by the system at the time the tests were made using only standard teletype equipment. For both the teletype and the binary signals, the frequency shift from "mark" to "space" was $60 \mathrm{cps}$. The envelope of the $417.05-\mathrm{Mc}$ carrier was simultaneously recorded on a second receiving system. (without $\mathrm{AGC}$ ) as explained previously.

Carrier measurements involving the use of the receiver combining circuits are not included in this report because these circuits were not in proper adjustment at the time the system tests were made. AFC was not used during these tests; however, the frequency drift indicator showed that the drift in the local oscillator was never greater than $\pm 10 \mathrm{cps}$, which was within the 300 -cps pass bands of the receiver system filters. Transmitting power levels were varied from approximately $500 \mathrm{w}$ to $4 \mathrm{kw}$, being constant for any one test.

System data pertinent to the tests are tabulated as follows:

\section{Millstone Hill, Mass., Station}

1. Coordinates $-42^{\circ} 36^{\prime} 48^{\prime \prime} \mathrm{N} ; 71^{\circ} 29^{\prime} 38^{\prime \prime} \mathrm{W}$.

2. Elevation-330 ft A.S.L. (ground level).

3. Azimuth of path, Millstone Hill to Sauratown Mt. $-230^{\circ} 33^{\prime} 37^{\prime \prime}$ clockwise from north.

4. Antennas - two, each $120 \mathrm{ft}$ by $120 \mathrm{ft}$ parabolic reflectors with feed horn at focus.

5. Estimated plane wave antenna gain-41.2 db. Antenna beam width approximately $1^{\circ}$.

6. Antenna spacing normal to propagation pathapproximately $150 \lambda$ (at $417 \mathrm{Mc}$ ).

7. Antenna line loss - approximately $1 \mathrm{db}$.

8. Optical horizon $-+15 \mathrm{~min}$.

9. Distance to optical horizon-approximately 4 miles.

10. Distance from Millstone Hill to Sauratown Mt. - 638 statute miles.

$$
\text { Sauratown Mt., N.C., Station }
$$

1. Coordinates $-36^{\circ} 22^{\prime} 52^{\prime \prime} \mathrm{N} ; 80^{\circ} 21^{\prime} 22^{\prime \prime} \mathrm{W}$.

2. Elevation-1915 ft A.S.L. (ground level).

3. Azimuth of path, Sauratown Mt. to Millstone Hill $-44^{\circ} 54^{\prime} 24^{\prime \prime}$ clockwise from north. 
4. Antennas - two, each $120 \mathrm{ft}$ by $120 \mathrm{ft}$ parabolic reflectors with feed horn at focus.

5. Estimated plane wave antenna gain- $41.2 \mathrm{db}$. Antenna beam width approximately $1^{\circ}$.

6. Antenna spacing normal to propagation pathapproximately $150 \lambda$ (at $417 \mathrm{Mc}$ ).

7. Antenna line loss - approximately $1 \mathrm{db}$.

8. Optical horizon $-20 \mathrm{~min}$.

9. Distance to optical horizon $\rightarrow 10$ miles.

10. Angular distance[1] ${ }^{2}-130.7$ milliradians (calculated, corrected for refraction.).

11. Receiver noise figure - approximately $5 \mathrm{db}$.

12. Measured equivalent noise power levels of the G.E. receivers over an "effective" bandwidth of approximately $150 \mathrm{cps}$ -

- $148.0 \mathrm{dbm}$ (decibels below 1 milliwatt) for receiver 1 ,

$-145.0 \mathrm{dbm}$ for receiver 2 ,

$-146.5 \mathrm{dbm}$ (estimated) for receiver 3 , and

$-146.5 \mathrm{dbm}$ (estimated) for receiver 4 .

\section{Experimental Results}

The results of the tests are separated into two categories: (1) The effects of the path on the characteristics of the received radio carrier. These measurements were made using an unmodulated carrier at the low-pilot frequency of $417.05 \mathrm{Mc}$ and (2) measurements of teletype and binary signal errors.

The factors involved in the first of the above two classifications of results are: power levels, amplitude distribution, fade rate (at median or other levels), fade duration distribution, power spectrum, variation of the 30-min medians, transmission loss, and diversity measurements; all of these factors were considered in terms of the envelope of the received radiofrequency carrier. The second category above deals with measurements of the teletype and binary signal errors in terms of carrier-to-noise $\left(\mathrm{C} / \mathrm{N}^{*}\right)$ ratios and receiving system bandwidths.

\subsection{Characteristics of the Received Carrier Envelope}

The equipment used to obtain cumulative distributions of the received (and recorded) radio carrier envelope amplitudes and the fade rates was similar to that used by Watt and Maxwell [2]. The fade duration distributions were obtained by modifying the equipment so that only those fades exceeding a particular preset duration would be registered.

\section{a. Received Power Levels and Amplitude Distributions}

The range of power levels and the types of amplitude distributions obtained for the received carrier envelope are shown in figure 2. Preliminary test runs showed that sample times greater than $20 \mathrm{~min}$ were required in order to obtain a statistically reliable sample of the carrier envelope. In most

\footnotetext{
${ }^{2}$ Figures in brackets indicate the literature references at the end of this paper.
}

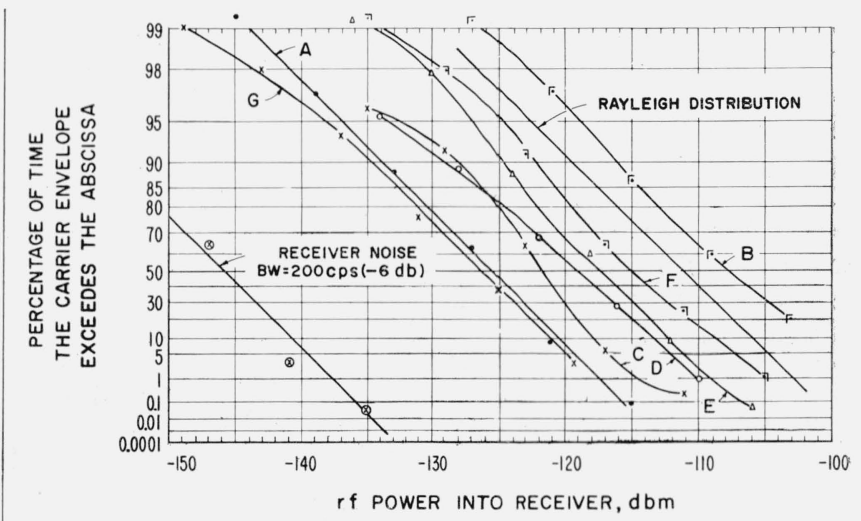

Figure 2. Typical cumulative distributions of carrier envelope amplitudes.

$$
\begin{gathered}
\text { Sauratown Mt., N.C. } \\
\text { Carrier frequency }=417.05 \mathrm{Mc} \\
\text { Transmission from Milstone Hill, Mass. } \\
\text { System BW de to } 42 \text { cps and de to } 650 \text { cps }(-6 \mathrm{db}) \\
\text { Transmitting and receiving antennas } \\
120 \text {-ft square paraboloids } \\
\text { Sampling period } 30 \text { min }
\end{gathered}
$$

\begin{tabular}{|c|c|c|c|c|c|c|}
\hline Run & Curve & $\begin{array}{c}\text { Transmitter } \\
\text { power }\end{array}$ & $\begin{array}{l}\text { Date } \\
1958\end{array}$ & $\begin{array}{l}\text { Time } \\
\text { e.s.t. }\end{array}$ & Median & $\begin{array}{l}\text { Transmis- } \\
\text { sion loss }\end{array}$ \\
\hline 1. & A & $k w$ & $5-22$ & 1440 & $\begin{array}{l}\mathrm{dbm} \\
-125.6\end{array}$ & $d b$ \\
\hline & B & 3 & $7-10$ & 1745 & -107.7 & 170.5 \\
\hline $4 \ldots$ & C & 3 & $7-11$ & 1350 & -121.6 & 184.4 \\
\hline 5 & D & 3 & $7-11$ & 2020 & -119.0 & 181.8 \\
\hline & $\mathrm{E}$ & 3 & $7-12$ & 2030 & -117.4 & 180.2 \\
\hline & $\mathrm{F}$ & 3 & $7-13$ & 1300 & -115.0 & 177.8 \\
\hline $19 \ldots$ & G & 1 & $7-15$ & 1450 & -126.0 & 184.0 \\
\hline
\end{tabular}

cases there is a similarity between the slopes of the measured distribution curves and the theoretical Rayleigh distribution. Curve $\mathrm{C}$ has the greatest departure from a Rayleigh distribution; however, the slope of a straight line best fitting the measured points closely approximates the slopes of the other measured distributions. As a matter of record, the data for curve $\mathrm{C}$ were obtained during a severe thunder storm at the receiving site and along most of the path of propagation, while data for curve D were obtained on the same day but $6 \mathrm{hr}$ later when the electrical storm had subsided. The difference between curves C and D probably could be attributed to the effects of lightning discharges. The range of the 30-min median values of the received power over the period of six days is seen to be approximately $19 \mathrm{db}$; however, $5 \mathrm{db}$ of this range can be attributed to a variation of the power level of the radiated carrier at the transmitter.

\section{b. Fade Rates}

The curves in figure 2 give an accurate statistical measure of the received power levels and the range of the variations of the received carrier envelope; however, these curves do not yield any information regarding the rates of fading, that is, the variation 
of the carrier envelope with time, at various power levels. A more restricted definition of carrier fade rate is: the average number of times that the carrier envelope passes through its median power level in one direction, per second. Fade-rate curves measured for two typical cases at various power levels are shown in figures 3 and 4 . These curves are contaminated by noise, particularly in the region of short duration fades (less than $100 \mathrm{msec}$ where a fade duration is defined as the time spent below a specific level. A more accurate measure of the short duration fades of the carrier envelope alone

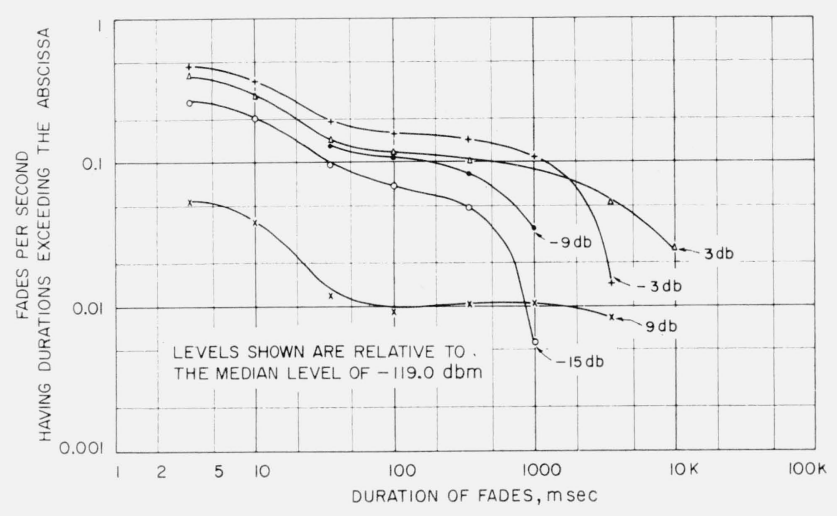

Figure 3. Carrier envelope fade duration and rate at various power levels.

Sauratown Mt., N.C.

Run 5, July 11, $1958-2008$ to 2038 e.s.t

Transmission from Millstone Hill, Mass.

Low pass bandwidth of system $=42 \mathrm{cps}(-6 \mathrm{db})$

Carrier frequency $=417.05 \mathrm{Mc}$

Transmitting and receiving antennas

120 -ft square paraboloids

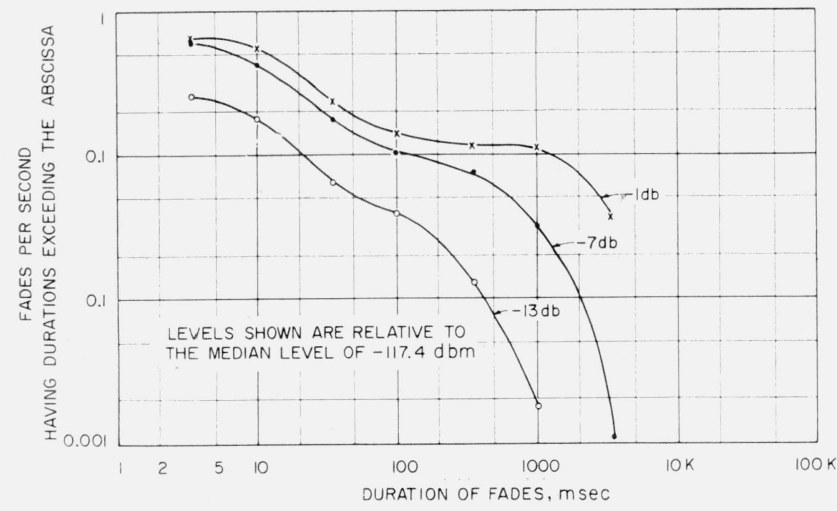

Figure 4. Carrier envelope fade duration and rate at various power levels.

Sauratown Mt., N.C.

Run 9, July 12, $1958-2016$ to 2046 e.s.t.

Transmission from Millstone Hill, Mass.

Low pass bandwidth of system $=42 \mathrm{cps}(-6 \mathrm{db})$

Carrier frequency $=417.05 \mathrm{Mc}$

Transmitting and receiving antennas

120 -ft square paraboloids would be obtained by extrapolating the "plateaus" of the curves into the short fade region. In previous work [3] this extrapolation procedure (for the median power level curves) yielded an approximate measure of the power spectrum width of the received carrier envelope. In this particular case we would obtain an average spectrum width of approximately $0.12 \mathrm{cps}$ from the curves in figures 3 and 4 . The pass band was limited to approximately 40 cps which was ample to pass most of the information on the carrier envelope amplitude variations, however, information on the noise characteristics above $40 \mathrm{cps}$ that is, fade durations below 25 msec, would be inaccurate.

The received signals were also analyzed to determine the percentage of time that the carrier envelope faded below particular power levels for a fade duration equal to or greater than chosen values. Typical results of this analysis are shown in figures 5 and 6 . A comparison between these sets of curves shows a greater percentage of short duration fade times for figure 5 than is shown in figure 6 . The curves shown in figures 5 and 6 are useful for modulation studies where it is desired to estimate the percentage message errors, taking into account the carrier fade duration as well as the median carrierto-noise ratio.

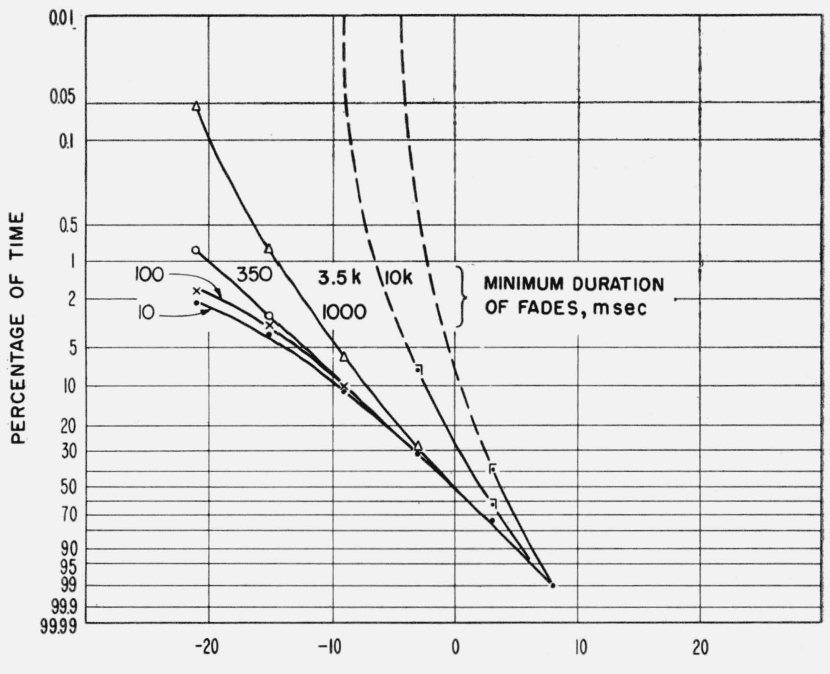

OBSERVING LEVEL, db RELATIVE TO MEDIAN LEVEL

Figure 5. Distribution of the carrier envelope fade duration showing the percentage of time that the carrier envelope fades to and remains below the level indicated by the abscissa, for a time duration exceeding the values indicated on the curves.

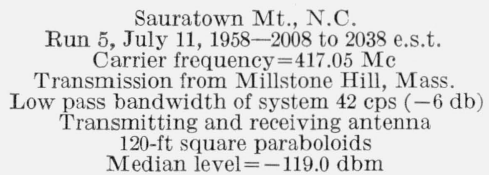

Sauratown Mt., N.C. 5, July 11, $1958-2008$ to 2038 e.s.t. Transmission from Millstone Hill, Mass w pass bandwidth of system $42 \mathrm{cps}(-6 \mathrm{db})$ 120 -ft square paraboloids 


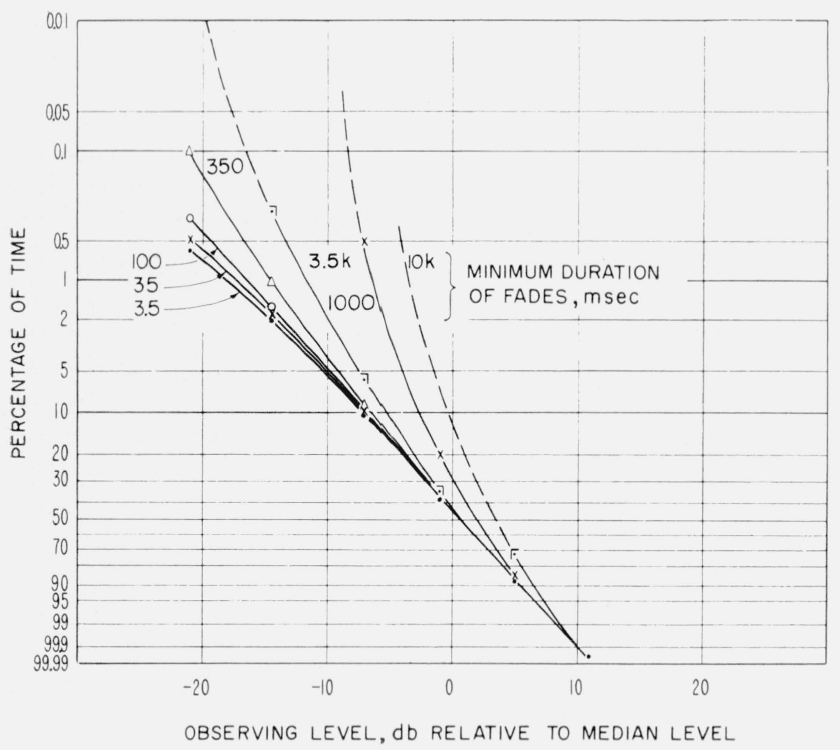

Figure 6. Distribution of the carrier envelope fade duration showing the percentage of time that the carrier envelope fades to and remains below the level indicated by the abscissa, for a time duration exceeding the values indicated on the curves.

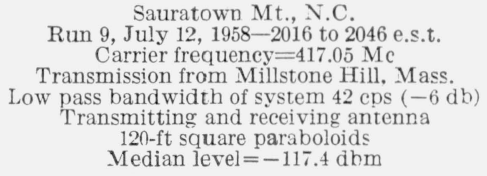

\section{c. Power Spectra}

The power spectra of the carrier envelope, shown in figure 7 , were obtained from playbacks of the magnetic tape recordings of the received carrier envelope. These results represent the bandwidth extremes for the tests covered by this report; selection was made in terms of extremes in fade rates. Discrete points on these curves were obtained by time averaging the power output level over an effective bandwidth of $0.041 \mathrm{cps}$ at a sweep frequency over the spectrum, of $0.001 \mathrm{cps}$.

The effective pass band of the "propagation path noise" is seen to be considerably less (by a factor of more than 25 to 1 ) than the bandwidth measured on a shorter tropospheric path [3]. The effective bandwidths, $B_{\text {eff }}$, tabulated in figure 7 are defined as the widths of rectangular spectra having the same total power as the measured spectra and with constant power densities equal to the maximum power density of the measured spectra. The slower fade rate (or narrower propagation path noise pass band) for the longer path might be attributed to the following factors: (1) A difference in the average heights of the paths above the earth and a consequent difference in the average characteristics of the paths; (2) very narrow antenna patterns were used for the long path, which would result in a reduction of multipath effects; and (3) the 2-to-1 ratio of carrier frequencies would also account for some of the difference in fade rate over the two paths.

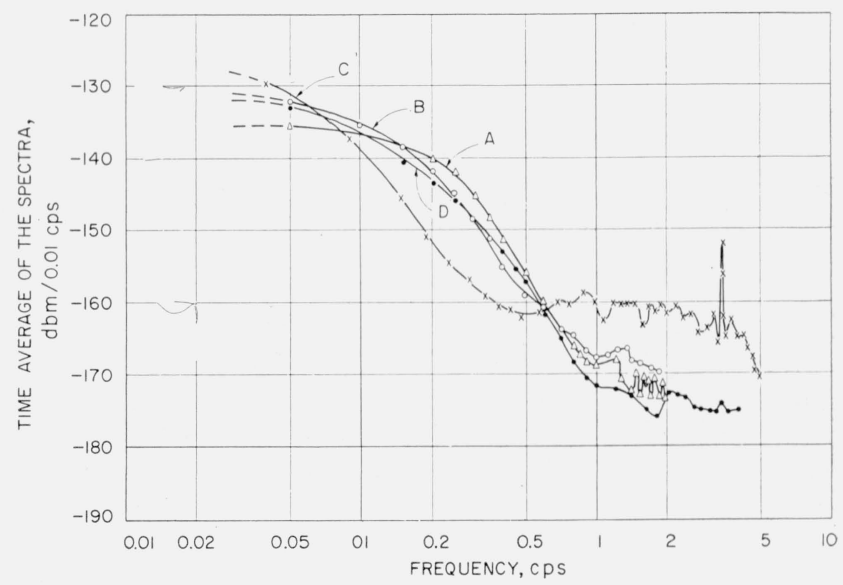

Figure 7. Typical power spectra.

$$
\begin{gathered}
\text { Sauratown Mt., N.C. } \\
\text { Carrier frequency=417.05 Mc } \\
\text { Transmission from Millstone Hill, Mass. } \\
\text { System (low pass) bandwidth 7.1 cps (-6 db) } \\
\text { Transmitting and receiving antennas } \\
\text { 120-ft square paraboloids } \\
\text { Sampling period, } 30 \text { min } \\
\text { July, 1958 }
\end{gathered}
$$

\begin{tabular}{|c|c|c|c|c|c|c|}
\hline $\bar{I}_{\text {Run }}$ & Curve & Date 1958 & Time e.s.t. & $\begin{array}{l}\text { Median } \\
\text { power level } \\
\text { of received } \\
\text { signal }\end{array}$ & $\begin{array}{l}\text { Total } \\
\text { average } \\
\text { spectrum } \\
\text { power }\end{array}$ & $\begin{array}{c}\text { Beff of } \\
\text { spectrum }\end{array}$ \\
\hline $\begin{array}{l}5 \ldots \ldots \\
9 \ldots \ldots \\
10 \ldots \\
24\end{array}$ & $\begin{array}{l}\mathrm{A} \\
\mathrm{B} \\
\mathrm{C} \\
\mathrm{D}\end{array}$ & $\begin{array}{l}7-11 \\
7-12 \\
7-13 \\
7-16\end{array}$ & $\begin{array}{l}2020 \\
2030 \\
1300 \\
1315\end{array}$ & $\begin{array}{l}d b m \\
-119.0 \\
-117.0 \\
-114.5\end{array}$ & $\begin{array}{l}d b m \\
-123.0 \\
-120.4 \\
-120.3 \\
-121.9\end{array}$ & $\begin{array}{l}c p s \\
0.17 \\
0.06 \\
0.07 \\
0.06\end{array}$ \\
\hline
\end{tabular}

The effect of reflections from airplanes [4] (along: the path) is clearly evident from curve $\mathrm{C}$ in figure 7 where there is an enhancement of power at frequencies above $0.5 \mathrm{cps}$. In some instances it was noted that the carrier envelope faded at a very uniform and regular rate of up to $7 \mathrm{cps}$ due apparently to reflections from airplanes. Lesser and varying amounts of "airplane fading" effects are seen from curves $\mathrm{A}, \mathrm{B}$, and D. It was also noted that lightning discharges have the effect of increasing the bandwidth of the propagation noise; this effect is perhaps due to a combination of reception of the energy from the lightning stroke and a short time enhancement of the carrier due to reflections from the ionized paths set up by the strokes.

It seems unlikely that a consideration only of these spectrum widths and spectrum power levels of the propagation noise would be sufficient to determine the effect of this noise on the message errors; due consideration should also be given to the duration of the carrier fades relative to the noise peaks at particular levels. However, the spectra shown by figure 7 do give a measure of the noise with which the signal must compete in terms of a resultant carrier amplitude or carrier envelope. The frequency modulation imposed on the resultant received carrier by the propagation path is expected to have a spectrum bandwidth of the same order as the above 
spectrum of the path propagation amplitude modulation noise [4]. From the table in figure 7 it is seen that the total average power of the transmission-path noise lies below the median power levels from 3.4 to $5.8 \mathrm{db}$; for a Rayleigh distributed signal the total spectrum power (i.e., variance) should be $5 \mathrm{db}$ below the median power level of the signal.

\subsection{Transmission Loss}

The predicted hourly median transmission loss distribution for the Millstone Hill of Sauratown Mt. tropospheric path is shown in figure 8; the probable error of the predicted median is plotted relative to the predicted median curve. This calculated distribution of the median transmission loss was made

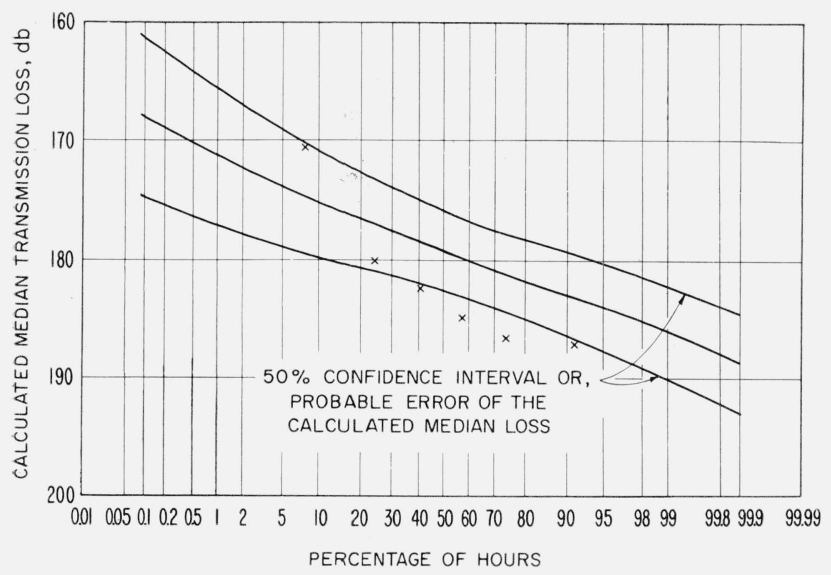

Figure 8. Calculated transmission loss.

Calculated distribution of hourly median of transmission loss for summer afternoon and evening

Transmission from Millstone Hill, Mass. to Sauratown Mt., N.C. frequency, $417 \mathrm{Mc}$

$$
\begin{aligned}
& \text { X-measured values, six half hour medians } \\
& \text { Transmission and receiving antennas } \\
& \text { 120-ft square paraboloids } \\
& \text { Path length, } 638 \text { statute mi } \\
& \text { Angular distance, 130.7 milli-radians } \\
& \text { Path antenna gain } 73 \mathrm{db}
\end{aligned}
$$

assuming that each antenna line loss was $1 \mathrm{db}$ and that the antenna-to-medium coupling loss was 4.7 $\mathrm{db}$ for each antenna. The plane wave gain was estimated to be $73 \mathrm{db}$. If the assumption is made that the antennas are loss-free, that is, if the ohmic losses, ground losses, etc., are negligible, then the basic transmission loss or, what is also known as the path transmission loss, can be obtained by adding $73 \mathrm{db}$ to the curve values in figure 8 .

Measurements of the transmission loss were made in terms of the power input to the transmitting terminals and the available median power level at the receiving antenna; an allowance of $1 \mathrm{db}$ was made for antenna line loss at the transmitter and at the receiver. If the antennas are assumed to be loss-free, the above measurements of the system loss from the input to the transmitting antenna to the receiving antenna are equivalent to the transmission loss.

Measured values of the median transmission loss are tabulated in figure 2 and the cumulative distribution of these measured medians is shown in figure 8 . The measured values of the median transmission loss are slightly higher than the predicted values, perhaps due to the limited number of samples. However, it should be noted that the estimated antenna to medium coupling losses and the possible improper pointing of the antennas are involved in the slight discrepancy between the predicted and the measured transmission loss.

\subsection{Diversity Measurements}

Five types of dual-diversity measurements were made; four of the measurements were made with spaced antennas and one was made using crossed polarization transmission with single antennas at each end of the radio link. The results of these tests are shown in table 1.

\begin{tabular}{|c|c|c|c|c|c|c|c|c|c|}
\hline \multirow{3}{*}{ Run } & \multirow{3}{*}{ Test conditions } & \multirow{3}{*}{$\begin{array}{l}\text { Trans- } \\
\text { mission } \\
\text { paths } \\
\text { (See } \\
\text { fig. 9) }\end{array}$} & \multicolumn{2}{|c|}{ Polarization } & \multirow{2}{*}{\multicolumn{5}{|c|}{$\begin{array}{c}\begin{array}{c}\text { Cross-correlation coefficient of received signal } \\
\text { amplitudes }\end{array} \\
\tau, \mathrm{sec}\end{array}$}} \\
\hline & & & \multirow{2}{*}{ Trans. } & \multirow{2}{*}{ Rec. } & & & & & \\
\hline & & & & & 0 & 5 & 10 & -5 & -10 \\
\hline 5 & $\begin{array}{l}\text { One transmitting antenna, two receiving antennas; diverging path } \\
\text { transmission. }\end{array}$ & $A \& C$ & $\mathrm{H}$ & $\mathrm{H} \& \mathrm{H}$ & 0.14 & 0.06 & -0.10 & 0.11 & 0.03 \\
\hline 9 & Transmission.... & $A \& C$ & $\mathrm{H}$ & $\mathrm{H} \& \mathrm{H}$ & .08 & -.05 & -.10 & .09 & .10 \\
\hline 25 & $\begin{array}{l}\text { Two transmitting antennas, one receiving antenna; converging path } \\
\text { transmission. }\end{array}$ & $A \& B$ & $\mathrm{H} \& \mathrm{~V}$ & $\mathrm{HV}$ & .20 & .21 & .22 & .30 & -.05 \\
\hline 24 & $\begin{array}{l}\text { One transmitting antenna, one receiving antenna; crossed-polarization } \\
\text { one path transmission. }\end{array}$ & A & $\mathrm{HV}$ & $\mathrm{HV}$ & a1. 0 & & & & \\
\hline 26 & $\begin{array}{l}\text { Two transmitting antennas, two receiving antennas; parallel-paths } \\
\text { transmission. }\end{array}$ & $A \& D$ & $\mathrm{H} \& \mathrm{~V}$ & $\mathrm{H} \& \mathrm{~V}$ & 0.13 & .05 & -.03 & .06 & -.02 \\
\hline 28 & $\begin{array}{l}\text { Two transmitting antennas, two receiving antennas; crossed-path } \\
\text { transmission. }\end{array}$ & $B \& C$ & H \& V & $\mathrm{V} \& \mathrm{H}$ & .57 & -.15 & .10 & 0 & -.11 \\
\hline
\end{tabular}

Figure 9 shows the antenna arrangement, polarizations of the transmitted radio waves and the transmission paths involved in the system. It should be understood that the single-path transmission concept,

TABLE 1. Diversity measurements

a Obtained by visual inspection of paper chart records. 


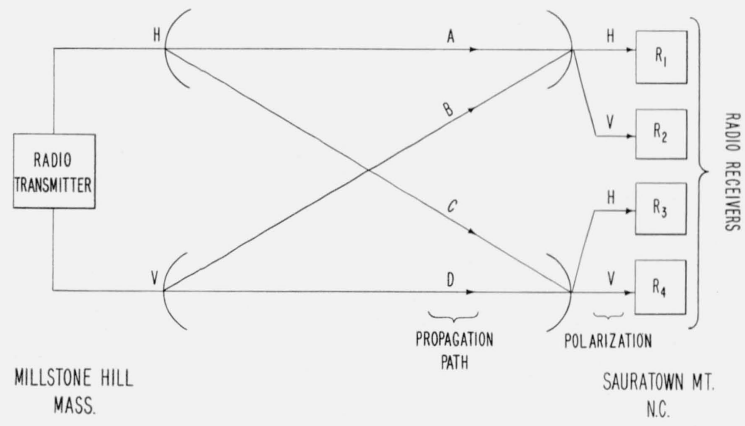

FIGURE 9. Block diagram of diversity system.

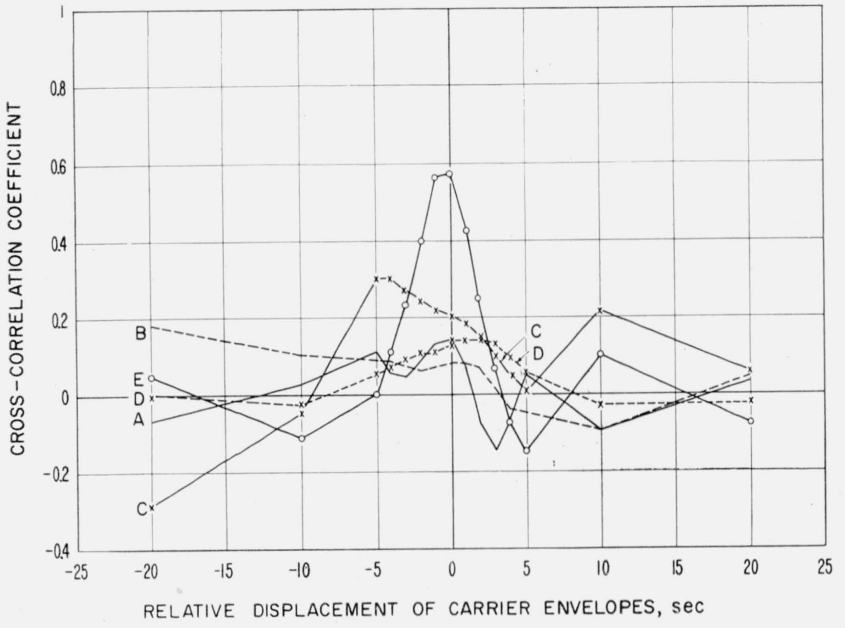

Figure 9a. Cross correlation of tropospheric carrier envelopes versus time displacement of the envelopes relative to each other

$\begin{gathered}\text { Transmission from Millstone Hill, Mass. } \\ \text { Reception at Sauratown Mt., N.C. } \\ \text { Frequency = 417 Mc }\end{gathered}$
Two antennas at each end of system
Antennas, 120-ft square paraboloids
Transverse spacing of antennas, $150 \mathrm{~h}$
July 1958

as outlined in figure 9, is an oversimplification of the nature of radio propagation but it is a convenient method of analysis in terms of the geometrical arrangement of the transmitting and receiving antennas.

From table 1 and also figures 9 and 9 a it can be seen that diversity is more effective (lowest correlation coefficient) for the cases where separate transmission paths are involved, that is, where no common volume of atmosphere exists at the path midpoint for two or more of the paths. Hence, space diversity would seem to be more eflective for the "diverging-path" (or "converging-path") type of sys- tem than for the "crossed-path" system since the cross-correlation coefficients were 0.08 to 0.20 and 0.57 , respectively. The cross-correlation coefficient for the parallel-path system is 0.13 which compares well with the diverging-path system.

The results shown in figure 9a indicate that radio wave propagation over the crossed paths $\mathrm{B}$ and $\mathrm{C}$ of figure 9 is not strictly independent and hence the system does not involve four mutually independent paths. However, the cross-correlation coefficient of approximately 0.6 for two of the four paths would still result in radio reception closely approximating that of quadruple diversity [6].

Curve $\mathrm{C}$ in figure 9a shows a slight numerical increase in the cross-correlation coefficient for time lags of minus 5 sec and minus 20 sec; these time lags correspond to transverse drift velocities of the common scatter volumes at the path midpoint of approximately $25 \mathrm{mph}$ and $6 \mathrm{mph}$, respectively; these figures being obtained from the geometry of the paths.

The crossed-polarization single-path test (run 24) gave a cross-correlation coefficient very close to unity. These results indicate that the propagation path fading was independent of the polarization of the radio waves. A close study of the paper chart records for the crossed-polarization tests showed also that the two received carrier envelopes varied identically when the carriers were reflected from an airplane surface.

\subsection{Teletype and Binary Signal Errors}

As explained previously, the teletype and binary signals at the output of the demodulator (see fig. 1) were recorded as frequency modulation of a 13.02-kc subcarrier on magnetic tape and were also recorded (printed out) by means of a teletype printer at the receiving site. The magnetic tape recorded signals were then played back in the laboratory (at Boulder) into a limiter-discriminator-teletype printer system and the teletype character errors were obtained from the teletype printer records.

The AGC action of the receiving system held the $13.02-\mathrm{kc}$ signal essentially constant at the output of the demodulator while varying the noise level at this point; hence the noise-to-signal level ratio was obtained from the magnetic tape playback by measuring the average noise power in a pass band of approximately $4 \mathrm{cps}$, placed $130 \mathrm{cps}$ above the $13.02-$ kc subcarrier.

A low-pass filter having an effective cutoff frequency of 100 cps was inserted in the limiter-discriminator output to the teletype printer in order to limit the noise power spectrum to the bandwidth which was required for the teletype signal.

The binary errors were measured by means of the system shown in block form in figure 10 . The binary signal from the FM limiter-discriminator was essentially constant in amplitude with time varying amounts of noise power as shown. The low-pass 13 -cps (effective) filter was adjusted to have a rise time somewhat longer than the gating period $0.05 \mathrm{~T}$; 


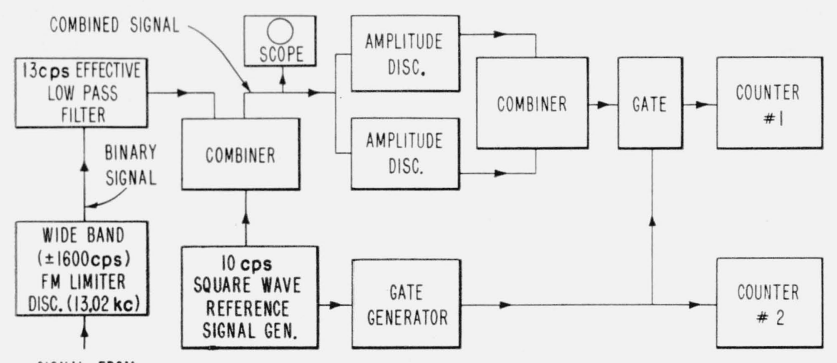

SIGNAL FROM

MAGNETIC TAPE

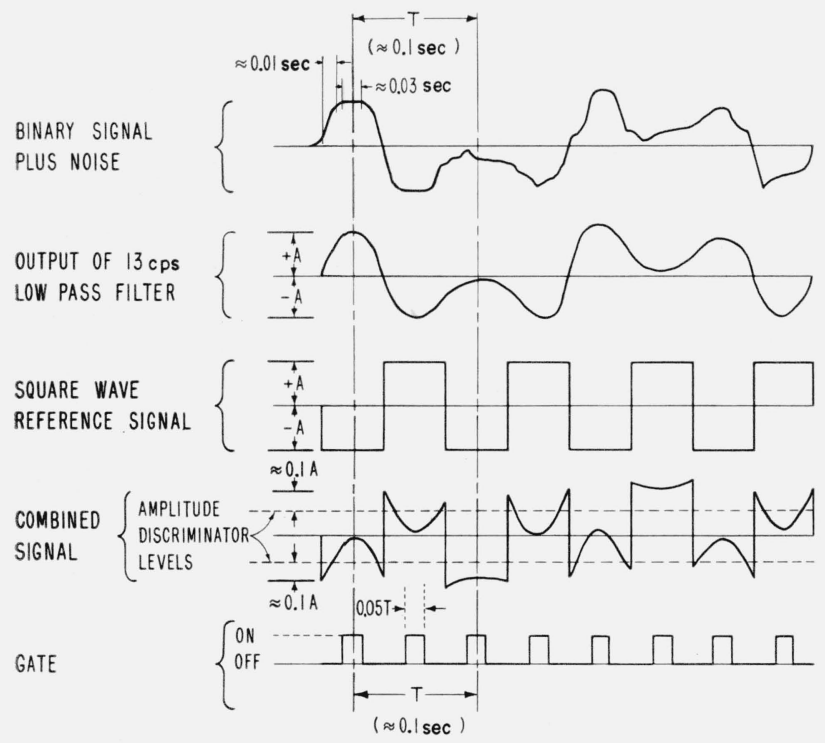

Figure 10. Binary-error measuring system.

hence the output level of this filter did not change appreciably during the gating period. Triggering levels of the amplitude discriminators were adjusted relative to the combined signal as shown; errors were registered on counter 1 only if the combined signal amplitude exceeded the settings of the discriminator levels during the gating period. In other words, an error was registered if the amplitude of the signal from the 13-cps low-pass filter was less than $0.1 \mathrm{~A}$ during the gating period. Counter 2 registered the total number of binary pulses occurring during the test period.

From the above it is seen that the errors were measured in terms of whether or not the combined amplitude of the signal plus noise was of the proper polarity and above a particular amplitude $(\approx 0.1 \mathrm{~A})$ during the center 10 percent of the signal peak duration. This method of measuring the binary errors conforms to the principles employed by the decision mechanism in the teletype printer.

The results of the teletype and the binary error measurements are shown in figure 11. At this point it should be noted that the effective pass band for the signal plus noise at the input to the limiter-dis-

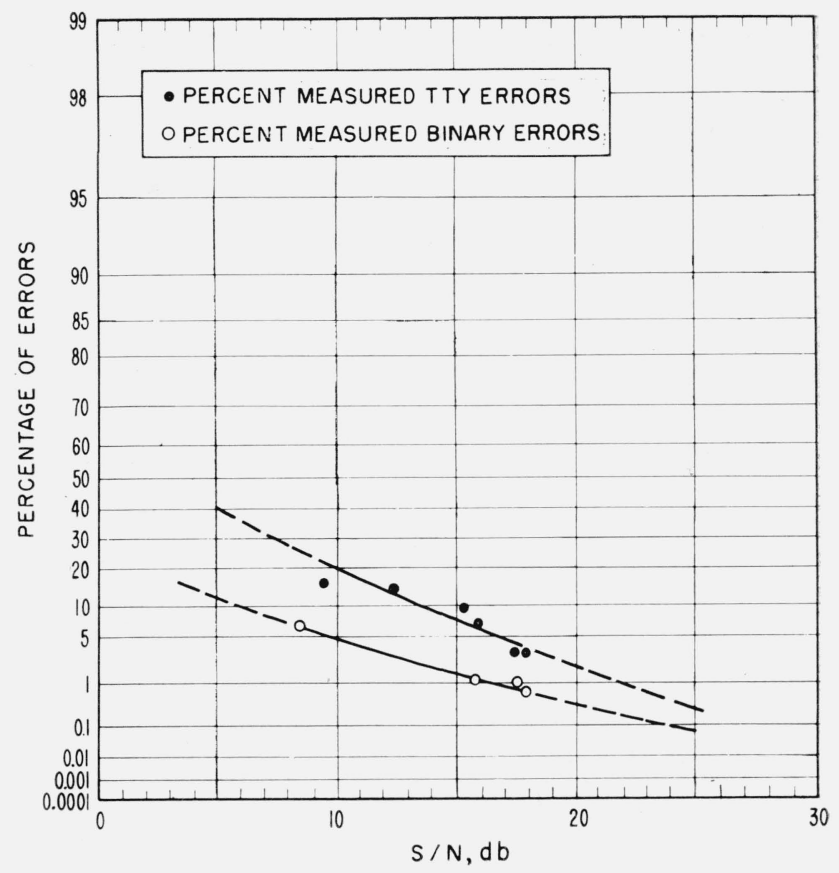

Figure 11. Narrow-band FSK teletype and binary errors versus $S / N$, for a fading carrier combined with thermal noise.

$\mathrm{S} / \mathrm{N}^{\top}$ is the ratio of the average signal power (FSK $13.02 \mathrm{kc}$ subcarrier) at the limited-discriminator input to the average noise power in a $290 \mathrm{cps}$ effective pass band.

$$
\begin{gathered}
\text { Sauratown Mt., N.C. } \\
\text { July } 1958 \\
\text { Transmission from Millstone Hill, Mass. } \\
\text { Signal sampling period } 30 \mathrm{~min} \\
\text { Carrier frequency }=417.05 \mathrm{Mc} \\
\text { Transmitting and receiving antennas } \\
\text { 120-ft square paraboloids }
\end{gathered}
$$

criminator was $290 \mathrm{cps}$ for both the teletype and the binary signals. It was not feasible to reduce the pass band for the binary signal below $290 \mathrm{cps}$ because of the frequency variation of the subcarrier frequency as obtained from the magnetic tape playback. However, the low-pass filter effective cutoff frequency in the discriminator output circuit for the teletype signal was $100 \mathrm{cps}$ while the effective cutoff frequency of the filter for the binary signal was 13 cps; the cutoff frequencies of these low-pass filters were made only wide enough to pass the binary and the teletype signal spectrums. Hence the ratio of the half passband of the limiter input signal to the low-pass limits of the discriminator output signal was approximately 1.4 for teletype signals and 11 for binary signals. These conditions are close to optimum for the teletype signal but not for the binary signal; that is, the noise-power bandwidth involved in the binary-signal error measurements was much greater than the required binary-signal bandwidth. The net result is that the measured binary errors are increased somewhat in terms of the carrier-to-noise ratio at the limiter input.

Attempts to correlate the measured teletype and binary errors with the short-time nature of the radio- 
frequency carrier indicated that the variation of the signal-to-noise ratio as a function of time at the output of the demodulator was dependent somewhat upon the functioning of the demodulator section of the radio receiving system; hence the results of the error measurements are plotted in figure 11 relative to the signal-to-noise ratios at the demodulator output rather than at the IF output. The cumulative distributions of the noise envelope at the demodulator output were measured; these measured distributions were used to determine the average noise power levels at this point. From figure 1 it is evident that when the low-pilot power level is comparable to the noise power level (in the low-pilot channel) the demodulator operates with relatively high noise power at both of its input points and this condition is expected to degrade the signal-to-noise ratio at the output of the demodulator as compared with the carrier-tonoise ratio at the IF output.

\section{Conclusions}

Measurements of the 417.05-Mc carrier envelope, transmitted over the tropospheric path from Millstone Hill, Mass. to Sauratown Mt., N.C., shows that the cumulative distribution of the instantaneous amplitude of this envelope for 30-min samples roughly approximated a Rayleigh type. Median power-level fade rates of the carrier over this 638mile path, using one-degree-beamwidth antennas, were less than $0.2 \mathrm{cps}$. During a small percentage of the time radio signal reflections from airplanes along the path resulted in uniform and large carrier amplitude variations at a rate of up to $7 \mathrm{cps}$. The measured characteristics of the carrier envelope indicate that the received resultant carrier, over this tropospheric path, resembles a noise signal over a very narrow band of frequencies. It appears as though the received carrier could be closely duplicated in the laboratory by passing a random noise signal through a bandpass filter; this filter would be centered at 417 $\mathrm{Mc}$ and its pass characteristics, on each side of the center frequency, would be as shown in figure 7 .

Path loss measurements checked within $3.5 \mathrm{db}$ of the calculated values, which were based on the work of P. L. Rice [7] et al.

Dual diversity measurements indicated that polarization diversity was ineffective over this path. It was also found that the diverging-path type of diversity is slightly more effective than the crossed-path type. Angular diversity, involving the use of multiple antenna feeds to produce slightly diverging antenna beams, should be investigated in this system.

Nondiversity error measurements as shown in figure 11 indicated that an average signal power to average noise power ratio (at the limiter-discriminator input) of approximately $20 \mathrm{db}$ gave a 2-percent teletype-character error rate and a corresponding binary error rate of approximately 0.3 percent. These error rates apply to a fading signal and an effective pass band at the limiter input of $290 \mathrm{cps}$. For opti- mum bandwidths the required signal-to-noise ratios would be determined by applying bandwidth corrections; the error rate thus obtained from figure 11 would be slightly pessimistic.

The results obtained during these tests give an accurate picture of the nature of the received tropospheric carrier as applied to this particular system and time. Furthermore, it is probable that these results roughly define the limits of power levels, fade rates, spectrum, etc., for other times of the day and the year for this system.

The authors are indebted to M. J. Ogas of the USAF for arranging for these tests, and to Lincoln Laboratory and General Electric Co. personnel for granting permission to carry out these tests. In particular we convey our appreciation to: G. L. Mellen, W. E. Morrow, James H. Chisholm, Donald G. Brennan, J. B. Long, Burt E. Nichols, Don MacLellan, and others of the Lincoln Laboratory; Frank Bias, A. Clark Gunn, Alex Alviros, T. G. Custin, George Rose, and others of the General Electric Co.

We also thank Herbert Wallace and William Collins of the Page Communication Co., and Sergeant John W. Samuelson of the USAF and his group for their assistance in carrying out the tests.

Spectrum analysis work was done by Paul I. Wells and James A. Sykes. Cross correlation analysis of the diversity records was carried out by Harris Janes, A. W. Kirkpatrick, and Mrs. Vivian Fuller. Transmission-loss calculations were made by A. P. Barsis.

\section{References}

[1] K. A. Norton, P. L. Rice, and L. E. Vogler, The use of angular distance in estimating transmission loss and fading range for propagation through a turbulent atmosphere over irregular terrain, Proc. IRE 43, No. 10,1488 (1955).

[2] A. D. Watt and E. L. Maxwell, Measured statistical characteristics of vlf atmospheric radio noise, Proc. IRE 45, No. 1, 55 (1957).

[3] A. F. Barghausen, H. B. Janes, F. O. Guiraud, S. Murahata, and C. F. Peterson, Measurements of the power spectra of fading in tropospheric scatter propagation (unpublished report).

[4] G. L. Mellen, W. E. Morrow, A. J. Pote, W. H. Radford, and J. B. Wiesner, Uhf long-range communications systems, M.I.T. Tech. Rept. No. 91, 5 (1955).

[5] T. Hagfors and B. Landmark, Simultaneous variation of amplitude and phase of gaussian noise, with applications to ionospheric forward-scatter signals, Proc. Inst. Elec. Engrs., Pt. B 105, 555 (1958).

[6] H. Staras, Diversity reception with correlated signals, J. Appl. Phys. 27, 93 (1956).

[7] P. L. Rice, A. G. Longley and K. A. Norton, Prediction of the cumulative distribution with time of ground wave and tropospheric wave transmission loss (to be published).

Boulder, Colo.

(Paper 64D2-46) 